\title{
Coding quality of deaths and its impact on elderly unintentional fall mortality data from 1990 to 2019: a retrospective analysis of the WHO Mortality Database
}

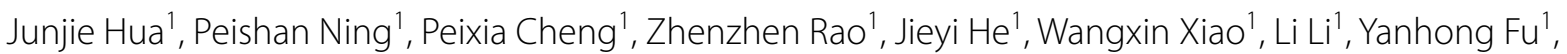
Ruotong $\mathrm{Li}^{1}$, Jie Li ${ }^{1}$, Wanhui Wang ${ }^{1}$, David C. Schwebel ${ }^{2}$ and Guoqing $\mathrm{Hu}^{{ }^{*}}$

\begin{abstract}
Background: Several studies have assessed the reporting quality of all-cause mortality data from the WHO Mortality Database, but little is known about coding quality and its impact on elderly unintentional fall mortality data worldwide. We aimed to assess the coding quality of deaths and its impact on elderly unintentional fall mortality.

Methods: Using data from the WHO Mortality Database, 1990-2019, we calculated the number of countries/territories that had mortality data in the database, and the proportion of deaths with five types of problematic codes based on the 10th International Classification of Disease (unspecified deaths, injury deaths with undetermined intent, unspecified unintentional injury, unintentional falls with unspecified mechanism, unintentional falls with unknown occurrence place). We estimated age-adjusted unintentional fall mortality before and after correcting problematic codes.

Results: Only 64\% (124/194) of WHO member states had at least 1 year of mortality data in the database during 1990-2019, and data unavailability was more common for underdeveloped countries/territories than for developed countries/territories. Coding quality was poor for many countries/territories. Among the study years when countries/ territories possessed mortality data, $80,53,51$, and $63 \%$ had a proportion of unintentional fall deaths with unspecified mechanism over 50\% in low-income, lower middle-income, upper middle-income, and high-income countries/ territories, respectively; comparable proportions for unintentional fall deaths with unknown occurrence place were $100,42,71$, and $62 \%$. Among the 94 countries/territories having mortality data, problematic codes caused a relative mortality difference $\geq 50 \%$ in 59 countries/territories (63\%). After correcting problematic codes, 5 of 55 countries/ territories with data witnessed a reverse in mortality changes between 2005 and 2015 . Among the 82 countries/territories with mortality data for 5 or more years, 18 countries/territories (22\%) experienced a directional reverse in linear regression coefficient.
\end{abstract}

\footnotetext{
*Correspondence: huguoqing009@gmail.com

${ }^{1}$ Department of Epidemiology and Health Statistics; Hunan Provincial Key Laboratory of Clinical Epidemiology, Xiangya School of Public Health; National Clinical Research Center for Geriatric Disorders, Xiangya Hospital, Central South University, Changsha 410078, China

Full list of author information is available at the end of the article
} permits use, sharing, adaptation, distribution and reproduction in any medium or format, as long as you give appropriate credit to the original author(s) and the source, provide a link to the Creative Commons licence, and indicate if changes were made. The images or other third party material in this article are included in the article's Creative Commons licence, unless indicated otherwise in a credit line to the material. If material is not included in the article's Creative Commons licence and your intended use is not permitted by statutory regulation or exceeds the permitted use, you will need to obtain permission directly from the copyright holder. To view a copy of this licence, visit http://creativecommons.org/licenses/by/4.0/. The Creative Commons Public Domain Dedication waiver (http://creativeco mmons.org/publicdomain/zero/1.0/) applies to the data made available in this article, unless otherwise stated in a credit line to the data. 
Conclusions: The availability and coding quality of global data related to elderly unintentional fall mortality was poor between 1990 and 2019. When data are available, varying coding quality across countries/territories and over time have a substantial impact on mortality estimates and mortality comparisons. Global agencies plus each individual government should be aware of the importance of collecting and sharing high-quality mortality data, and take action to improve data quality for inclusion in the WHO Mortality Database.

Keywords: Unintentional fall, Mortality, Data availability, Coding quality, WHO Mortality Database

\section{Introduction}

High-quality death data form a base to develop health policies, conduct health research, and make healthrelated decisions [1]. Mortality has been selected as the indicator to assess progress in several targets of the Sustainable Development Goals (SDGs), such as maternal mortality (SDG 3.1), newborn and child mortality (SDG 3.2), and road traffic injuries (SDG 3.6) [2]. The World Health Organization (WHO) requests its member states to report basic death data to the WHO annually and compiles these data into the WHO Mortality Database [3].

Currently, the WHO Mortality Database is the only open-access mortality data source that details deaths from specific International Classification of Disease (ICD) codes in the world. WHO mortality data have been frequently used by other international organizations like World Bank, the Global Burden of Disease (GBD) study group, and health researchers [4-7]. It is concerning, therefore, that data users may not realize that data quality from many low- and middle-income countries in the WHO Mortality Database is not as high as those from high-income countries $[3,8]$.

A limited number of previous studies have assessed the reporting quality of all-cause mortality data from the WHO Mortality Database [5, 8-10]. Although valuable, the results of these studies are difficult to compare because they use different quality indicators and examine data across different study time periods. In addition, previous studies relied on general quality indicators to assess the reporting quality of all-cause mortality data, inadequately reflecting the reporting quality of specific causes of death relevant to policy-making like unintentional falls among old adults.

Elderly falls have been a leading cause of global unintentional injury deaths for many years [11], and as the population gets older, elderly falls have become an increasingly important public health challenge worldwide [12]. Two publications adopted the WHO mortality data to examine changes in fall-related mortality from 2010 to 2014 in the United States [13] and between 2006 and 2016 in Australia and the United Kingdom [14], but neither assessed the reporting quality of fall-related mortality data and its impact on the results. Three studies evaluating the reporting quality of fall mortality in the
United States suggested that the recent reporting quality of mortality data has improved substantially and therefore created an artificial impression of potential impact of sharply increasing rates of elderly unintentional fall mortality [15-17]. Research evidence, however, is absent for all other countries and territories included in the WHO Mortality Database.

Using a set of unified quality indicators, we assessed the reporting quality of elderly fall deaths for all countries and territories included in the WHO Mortality Database and its impact on elderly fall mortality rates from 1990 to 2019.

\section{Methods}

Data source

Data were obtained from the WHO Mortality Database, which collects the number of deaths by country/territory, year, cause of death, sex, and age group since 1950 and allows free online access to the aggregated data online. Four versions (7th to 10th revisions) of the International Classification of Disease (ICD) were used to code the deaths by different countries across different time periods [3]. The WHO Mortality Database is updated regularly, with the update used in this manuscript occurring in March 2021.

Population data for each country/territory were derived from the estimates and projections of United Nations (UN) World Population Prospects 2019 (WPP 2019). The population by country/territory, year, sex, and age is available from 1950 to 2100 [18].

\section{Quality measures of mortality data}

Because limited data were available in the WHO Mortality Database, we used two types of indicators to assess the quality of unintentional fall mortality data; these indicators were selected based on previously published literature $[8-10]$.

a. Data availability: We used the presence of mortality data in the WHO Mortality Database to reflect data availability for free access from each country/ territory and year. Since most countries/territories started to use the ICD-10 codes to classify deaths in the 1990s, we chose the time period of 1990-2019 for this study's focus. We divided the study time period 
of 1990-2019 into seven groups to reflect data availability for a particular amount of time from each country/territory: 0years (unavailable), 1-5years, 6-10years, $11-15$ years, $16-20$ years, $21-25$ years, or 26-30years. In addition, we reported the version of ICD that each country/territory used to code deaths in each year. We limited data quality analysis to the years that countries/territories adopted the ICD-10 to code the deaths.

b. Coding quality: Based on previous frameworks for classifying and coding injury morbidity and mortality $[19,20]$, we defined five types of problematic ICD-10 codes related to unintentional falls: (1) unspecified deaths (ICD-10 codes: R96, R98, R99), (2) injuries with undetermined intent (ICD-10 codes: Y30, Y31, Y34, Y87.2, Y89.9), (3) unspecified unintentional injuries (ICD-10 codes: X59), (4) unintentional falls with unspecified mechanism (ICD-10 codes: W19), and (5) unintentional falls with unknown occurrence place (the fourth digit code of W00-W19 is 9). The first three types of problematic codes have an impact on the estimate of overall unintentional falls mortality, while the latter two types of problematic codes affect the estimates of subgroup unintentional fall mortality by mechanism and by occurrence place. The proportion of five types of problematic codes was calculated as follows:

$$
\begin{aligned}
& \text { Proportion one }=\frac{\text { Number of unspecified deaths }}{\text { Number of total deaths }} \times 100 \% \\
& \text { Proportion two }=\frac{\text { Number of injury deaths with undetermined intent }}{\text { Number of injury deaths }} \times 100 \% \\
& \text { Proportion three }=\frac{\text { Number of unspecified unintentional injury deaths }}{\text { Number of unintentional injury deaths }} \times 100 \% \\
& \text { Proportion four }=\frac{\text { Number of unspecified unintentional fall deaths }}{\text { Number of unintentional fall deaths }} \times 100 \%
\end{aligned}
$$

of problematic codes affect the overall unintentional fall mortality, we applied the proportionate method to redistribute the first three types of problematic codes (unspecified deaths, injury deaths with undetermined intent, and unspecified unintentional injury deaths). When the proportion of deaths with problematic codes was less than $30 \%$ in a specific year, we used the proportions of causespecific deaths in the same year to redistribute deaths with problematic codes. When the proportion of deaths with problematic codes fell between 30 and $49 \%$ in a specific year, we used the proportions of cause-specific deaths for 3 years (the study year, the year before the study year, and the year after the study year) to redistribute deaths with problematic codes. When the proportion of deaths with problematic codes ranged between 50 and 69\% in a specific year, we used the proportions of cause-specific deaths of 5 years (the study year, the 2 years before the study year, and the 2 years after the study year) to redistribute deaths with problematic codes. When the proportion of deaths with problematic codes in a specific year was equal to or greater than $70 \%$, we used the proportions of cause-specific deaths of 7 years (the study year, the 3 years before the study year, and the 3 years after the study year) to redistribute deaths with problematic codes.

\section{Statistical analysis}

Stacked bar charts and geographic maps were used to present the availability of unintentional fall mortality from 1990 and 2019 in the WHO Mortality Database. The proportions of the five types of deaths with problematic ICD-10 codes were calculated for each year and for each country/territory. To demonstrate the coding quality of mortality data related to unintentional falls across countries/territories, we graphed the distribution of each of the five proportions of deaths with problematic codes by economic level of country/territory. According to the World Bank Analytical Classifications 2019 [22], we classified countries/territories into four categories: low-income countries/territories (LICTs), lower middle-income countries/territories (LMICTs), upper

$$
\text { Proportion five }=\frac{\text { Number of unintentioanl fall deaths with unknown occurrence place }}{\text { Number of unintentional fall deaths }} \times 100 \%
$$

\section{Models correcting problematic codes}

The proportionate method was used to correct (redistribute) problematic codes to cause-specific codes in a specific year for each country/territory. The proportionate method assumes that deaths with problematic codes follow the same cause distribution as deaths with specific codes, and thus could be redistributed to causespecific deaths [21]. Because only the first three types middle-income countries/territories (UMICTs), and higher-income countries/territories (HICTs). KruskalWallis rank sum test was used to examine differences in coding quality of unintentional fall mortality across the four income groups (Additional file 1: Appendix 1). In addition, we plotted trends in coding quality of unintentional fall mortality for each country/territory during the study period (Additional file 1: Appendix 2). 
To assess the impact of problematic codes on injury statistics, we compared age-adjusted unintentional fall mortality among adults aged 65 years and older before and after correcting (redistributing) deaths with problematic codes. The direct method and the new WHO World Standard Population [23] were used to calculate age-adjusted mortality rates. The ratio of corrected/ uncorrected mortality rate, computed based on the first three types of problematic codes (unspecified deaths, injury deaths with undetermined intent, and unspecified unintentional injury), was used to quantify the impact of deaths with problematic codes on each country's mortality estimates.

In addition, we employed two strategies to assess the impact of coding quality on mortality changes over time. First, we selected the 2 years (2005 and 2015) when most countries/territories had mortality data to compare mortality changes between 2005 and 2015 before and after correcting deaths with problematic codes. Second, for countries/territories with 5 or more years of mortality data, we fitted linear regression (with year as the independent variable and age-adjusted mortality as the dependent variable) and compared the regression coefficient before and after correcting deaths with problematic codes for each country/territory (Additional file 1: Appendix 3).

" $p \leq 0.05$ " was considered statistically significant for two-sided statistical tests. SAS version 9.4, $\mathrm{R}$ version 4.0.4, and Excel spreadsheet 2016 were used for data analysis. The research protocol was approved by the Medical Ethics Committee of Central South University on 25 January 2021 (No. XYGW-2021-06). We complied with the Guidelines for Accurate and Transparent Health Estimates Reporting (GATHER) recommendations [24]. All analyses, interpretations and conclusions are attributed to the authors, not to WHO, which is responsible only for providing the raw data.

\section{Results}

\section{Data availability}

Figure 1 shows the availability of unintentional fall mortality for older adults in the WHO Mortality Database from 1990 to 2019. Of the 194 WHO member states, 124 countries/territories had at least 1 year of death data in the WHO Mortality Database. During the study period, the number of countries/territories with mortality data was highest in 2009 (124) and lowest in 2019 (21); most countries/territories with death data in the WHO Mortality Database adopted the ICD-9 from 1990 to 1995; but during and after the mid-1990s, the number of countries/ territories adopting ICD-10 increased quickly (Fig. 1 A).
Of the countries/territories reporting data to the $\mathrm{WHO}$, those from the Americas, western and northern Europe, Russia, Australia, and New Zealand reported data for the greatest number of years; countries/territories from Africa, Southern Asia and Oceania tended to report for fewer or no years (Fig. 1 B).

\section{Coding quality}

Among the 102 countries/territories that reported death data to the WHO and used the 4-digit ICD-10 codes (104 or $10 \mathrm{M}$ lists) to classify the deaths, one was a lowincome country/territory (LICT), 13 were lower middleincome countries/territories (LMICTs), 31 were upper middle-income countries/territories (UMICTs), and 57 were high-income countries/territories (HICTs).

Figure 2A shows that the proportion of deaths with unspecified causes varied significantly across the four types of countries/territories $(p<0.01)$. LICTs had the highest proportion (median: 29.12\%, $P_{25}-P_{75}: 22.88$ $36.68 \%$ ) and HICTs the lowest (median: $0.68 \%, P_{25}-P_{75}$ : $0.20-1.94 \%$ ). Note that each point in the figure represents data from a single year and the six points for LICTs were all from the same country/territory.

The proportions of injury deaths with undetermined intent and unspecified unintentional injury deaths were also generally lower in countries/territories with high income than in those with low income (Fig 2B and C). Notably, four particular years in high-income countries/ territories had extremely high proportions of injury deaths with undetermined intent: 1998 for Saint Kitts and Nevis (100\%), 2002 for Cayman Islands (100\%), 2005 for Antigua and Barbuda (75\%), and 2009 for Saudi Arabia (71\%) (Fig. 2B). Similarly, for six particular years, individual high-income countries/territories reported a proportion of unspecified unintentional injury higher than $70 \%$ (Fig. 2C). Detailed reporting quality for the three measures for each country/territory and each year are available in the supplementary information (Additional file 1: Appendix 2).

Within the deaths that were coded as unintentional falls, the specificity involving the mechanism of falls and the occurrence place were highly similar and consistently poor (Fig. 3A and B). There were $80,53,51$, and $63 \%$ of study years having a proportion of unintentional falls with unspecified mechanism (W19) over 50\% in LICTs, LMICTs, UMICTs, and HICTs, respectively (Fig. 3A). The corresponding proportions for unintentional fall deaths with unknown occurrence place were 100, 42, 71 , and $62 \%$ for the four types of countries/territories (Fig. 3B). 

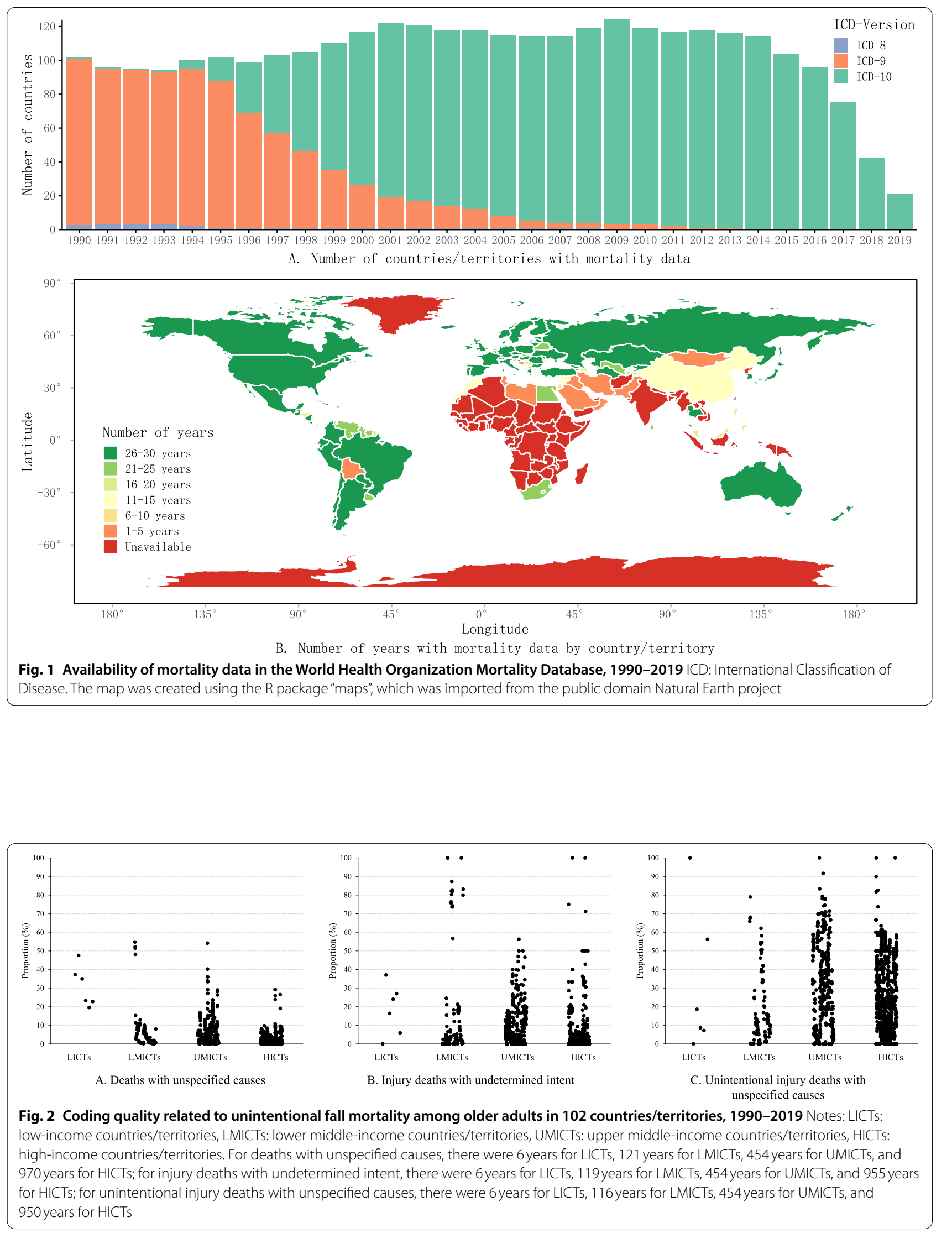


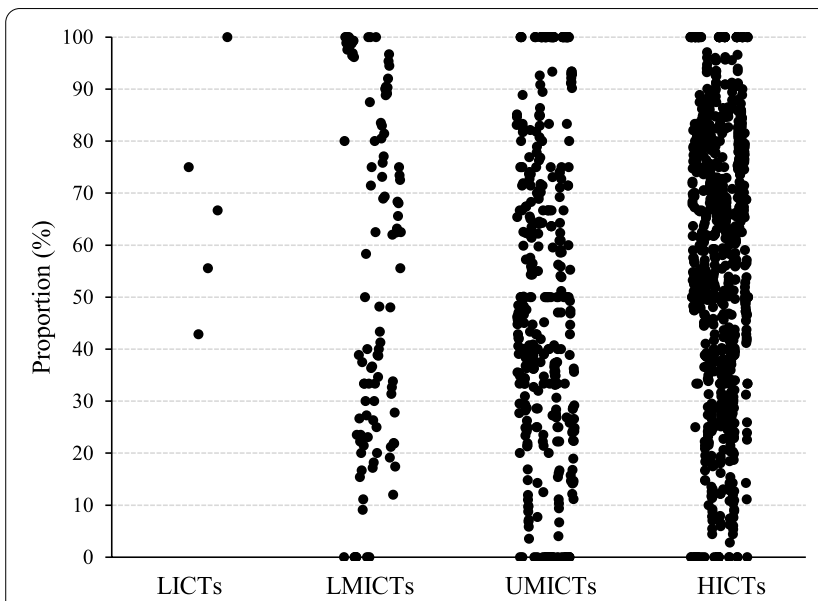

A. Unintentional falls with unspecified mechanism (W19)

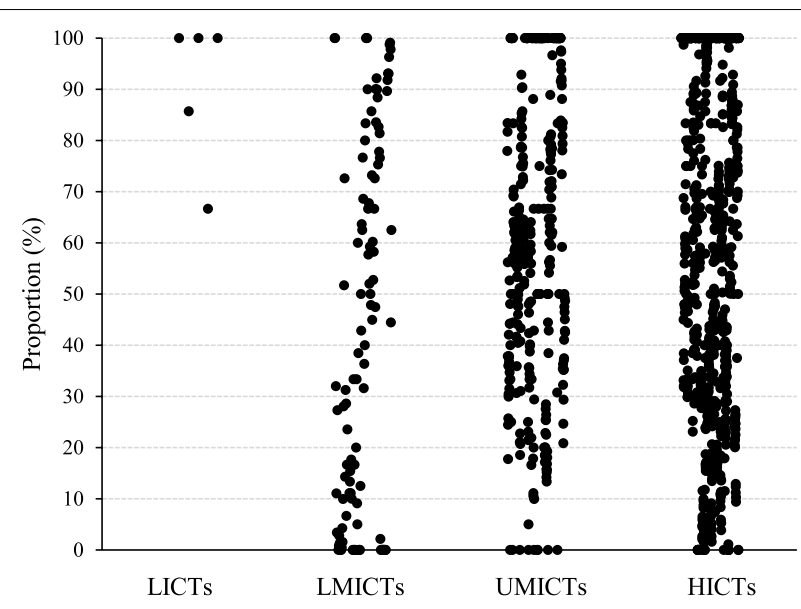

B. Unintentional falls with unknown occurrence place

Fig. 3 Coding quality of unintentional fall mortality among older adults in 102 countries/territories, 1990-2019 Notes: LICTs: low-income countries/territories, LMICTs: lower middle-income countries/territories, UMICTs: upper middle-income countries/territories, HICTs: high-income countries/territories. For unintentional fall deaths with unspecified mechanisms, there were 5 years for LICTs, 114 years for LMICTs, 414 years for UMICTs, and 875 years for HICTs; for unintentional fall deaths with undetermined occurrence place, there were 5 years for LICTS, 114 years for LMICTS, 411 years for UMICTs, and 841 years for HICTS

\section{Impact of coding quality}

Of 94 countries/territories having both available death data and population data, we calculated the ratio of age-adjusted unintentional fall mortality for adults aged 65 years and older before and after correcting three types of problematic codes (unspecified deaths, injury deaths with undetermined intent, and unspecified unintentional injury deaths), and divided the countries/territories into six categories based on the value of the mortality rate ratio between corrected and uncorrected age-adjusted unintentional fall mortality (note: the UN WPP2019 does not offer population estimates for 6 countries/territories). Table 1 illustrates largely inconsistent impacts of coding quality on elderly unintentional fall mortality across the 94 countries/territories. Six countries/territories (Belarus, New Zealand, Singapore, Cuba, Hungary, and Mongolia) had the best unintentional fall mortality data, with the maximum ratio of corrected/uncorrected age-adjusted unintentional fall mortality) ranging from 1.00-1.10. Remarkably, 59 countries/territories had poor data, with a ratio greater than $50 \%$.

When comparing changes in elderly age-adjusted unintentional fall mortality between 2005 and 2015 for the 55 countries/territories with mortality data, either the absolute rate difference or the relative rate changes, or both, changed somewhat over time in most countries/territories (Fig. 4A and B). Strikingly, increases became decreases in 4 countries (Belize, Denmark,
Israel, and Italy) and a reduction in Uruguay changed to be an increase after correcting the problematic codes. In addition, among countries/territories whose mortality changes remained in the same direction (increase or decrease) between 2005 and 2015, the largest alterations in relative mortality changes occurred in several countries, including Mauritius (from 607 to 273\%) and Paraguay (from 51 to $139 \%$ ).

Of the 82 countries/territories with mortality data for 5 or more years, 29 of the 48 countries/territories with positive regression coefficients were statistically significant $(p<0.05)$ before correction. 17 of the 34 countries/ territories with negative regression coefficients were statistically significant $(p<0.05)$ before correction (Table 2$)$.

Of the 48 countries/territories with positive regression coefficients, after correcting the problematic codes, the direction reversed in 5 countries/territories (Brazil, Dominican Republic, Israel, Italy, Luxembourg), the test results reversed to insignificant in 7 countries (Belgium, Brazil, Cyprus, Grenada, Italy, Mauritius, Morocco) and the test results reversed to significant in 3 countries (Iceland, Israel, Lithuania).

Of the 34 countries/territories with negative regression coefficients, after correcting the problematic codes, the direction reversed in 3 countries (Austria, Costa Rica, Peru), the test results reversed to insignificant in 2 countries (Austria, Norway) and the test results reversed to significant in 3 countries (France, Panama, Peru). 
Table 1 Ratio of unintentional fall mortality before and after correcting data coding in 94 countries/territories, 1990-2019

\begin{tabular}{|c|c|}
\hline Level of quality & Country/territory (number of years, median, minimum-maximum) \\
\hline Highest & $\begin{array}{l}6 \text { countries/territories: Belarus (1, 1.00, 1.00-1.00), New Zealand }(17,1.02,1.01-1.03) \text {, Singapore }(7,1.02,1.01-1.03) \text {, Cuba }(17,1.03 \text {, } \\
1.02-1.04) \text {, Hungary }(24,1.03,1.00-1.06) \text {, Mongolia }(1,1.03,1.03-1.03)\end{array}$ \\
\hline Higher & $\begin{array}{l}10 \text { countries/territories: Malta }(23,1.00,1.00-1.15) \text {, Switzerland (23, 1.07, 1.05-1.16), Turkey }(9,1.07,1.02-1.17) \text {, Estonia }(8,1.08, \\
\text { 1.05-1.12), Romania (20, 1.08, 1.04-1.13), Lithuania (20, 1.09, 1.04-1.18), Japan (23, 1.10, 1.07-1.14), Sri Lanka (8, 1.10, 1.05-1.13), } \\
\text { Bulgaria }(6,1.12,1.04-1.17) \text {, Poland (20, 1.16, 1.10-1.19) }\end{array}$ \\
\hline High & $\begin{array}{l}7 \text { countries/territories: Kuwait }(23,1.03,1.00-1.26) \text {, El Salvador }(19,1.11,1.03-1.26) \text {, United States of America }(19,1.14,1.11-1.25) \text {, } \\
\text { Kyrgyzstan }(17,1.16,1.05-1.23) \text {, Latvia }(11,1.17,1.11-1.22) \text {, Germany }(21,1.20,1.15-1.23) \text {, Greece }(4,1.27,1.19-1.29)\end{array}$ \\
\hline Low & $\begin{array}{l}8 \text { countries/territories: Belize }\left(20,1.01,1.00-1.40^{\mathrm{a}}\right) \text {, Croatia }(23,1.08,1.04-1.34) \text {, Armenia }(4,1.22,1.09-1.34) \text {, Republic of Moldova } \\
(12,1.25,1.17-1.33) \text {, Ireland }(9,1.27,1.16-1.36) \text {, Slovakia }(4,1.29,1.01-1.35) \text {, Spain }\left(19,1.30,1.25-1.40^{a}\right) \text {, Serbia }(1,1.34,1.34-1.34)\end{array}$ \\
\hline Lower & $\begin{array}{l}4 \text { countries/territories: China, Hong Kong SAR (17, 1.24, 1.11-1.48), Philippines (10, 1.28, 1.05-1.41), Honduras (6, 1.30, 1.26-1.49), } \\
\text { Brunei Darussalam }(4,1.34,1.18-1.44)\end{array}$ \\
\hline Lowest & 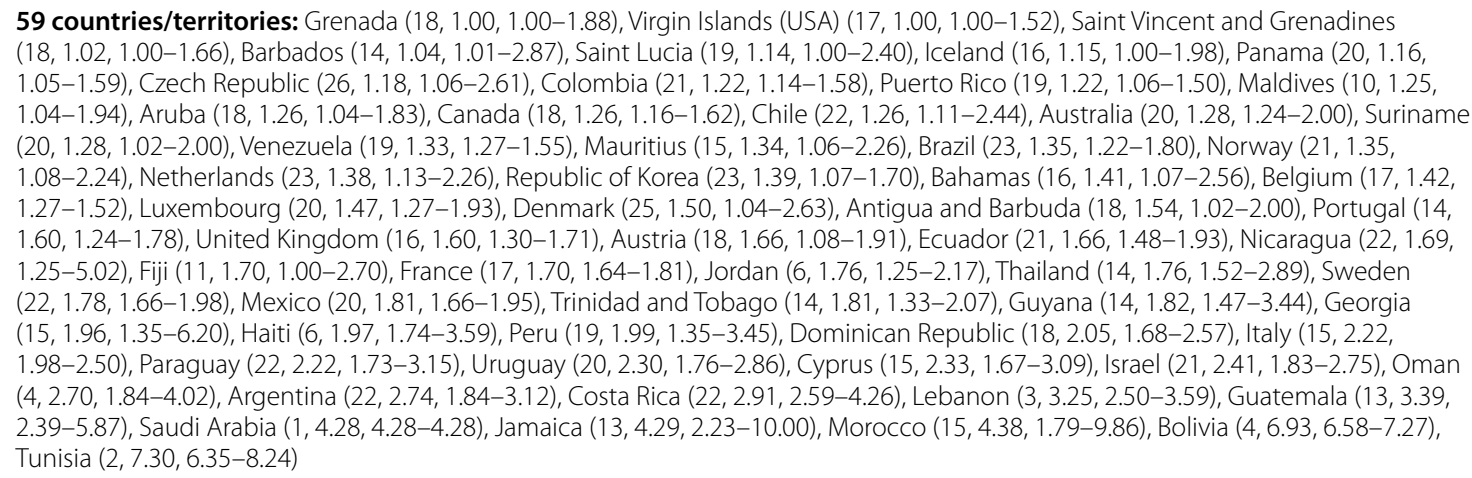 \\
\hline
\end{tabular}

Note: Countries were divided into six categories according to the maximum ratio of corrected/uncorrected unintentional fall mortality for adults aged 65 years and older: (1) highest, 1.00-1.09; (2) higher, 1.10-1.19; (3) high, 1.20-1.29; (4) low, 1.30-1.39; (5) lower, 1.40-1.49; (6) lowest, $\geq 1.50$

${ }^{a}$ The maximum value was less than 1.40 but was rounded to 1.40 when two decimal places were kept

\section{Discussion}

\section{Summary of main findings}

This study assessed reporting quality for elderly unintentional fall mortality data over the past three decades from the WHO Mortality Database and quantified the impact of reporting quality on estimated mortality data. The study generated three primary findings: (a) only $64 \%$ $(124 / 194)$ of WHO member countries reported mortality data to the WHO for at least 1 year during 1990-2019, and lack of reporting was more common for underdeveloped countries/territories in the WHO Mortality Database; (b) problematic codes related to elderly unintentional fall deaths were common for many countries/ territories with available data in the WHO Mortality Database, including frequent reporting of deaths coded as falls with unspecified mechanism (W19) and with unknown occurrence place; and (c) problematic codes largely or moderately distorted elderly unintentional fall mortality rates in certain years for some countries/territories, and therefore created potentially-misleading data to examine trends over time or compare elderly fall rates across countries/territories.

\section{Interpretation of findings Data unavailability}

Open data are critical to guide global, regional, and national public health actions like the post-2015 UN SDGs [25, 26]. Unfortunately, mortality data from 1990 to 2019 are unavailable in the WHO Mortality Database for $70 \mathrm{WHO}$ member states. This finding replicates the result from two earlier studies that indicated that the WHO Mortality Database did not have data from 75 countries in 1990-2003 [8] and that only 83 countries provided death registration data from 2000 to 2009 [27]. The results suggest minimal progress in data-sharing over time.

The lack of data in the WHO Mortality Database is generally ascribed to at least four causes. First, some countries/territories do not have a vital registration system to gather basic health indicators. For example, The Indian national vital registration system is still under development [28]. Second, the vital registration system in some countries was destroyed by political turmoil and war (e.g., Iraq, Syria, Libya) [29, 30]. Third, some countries/territories have not adopted the ICD 


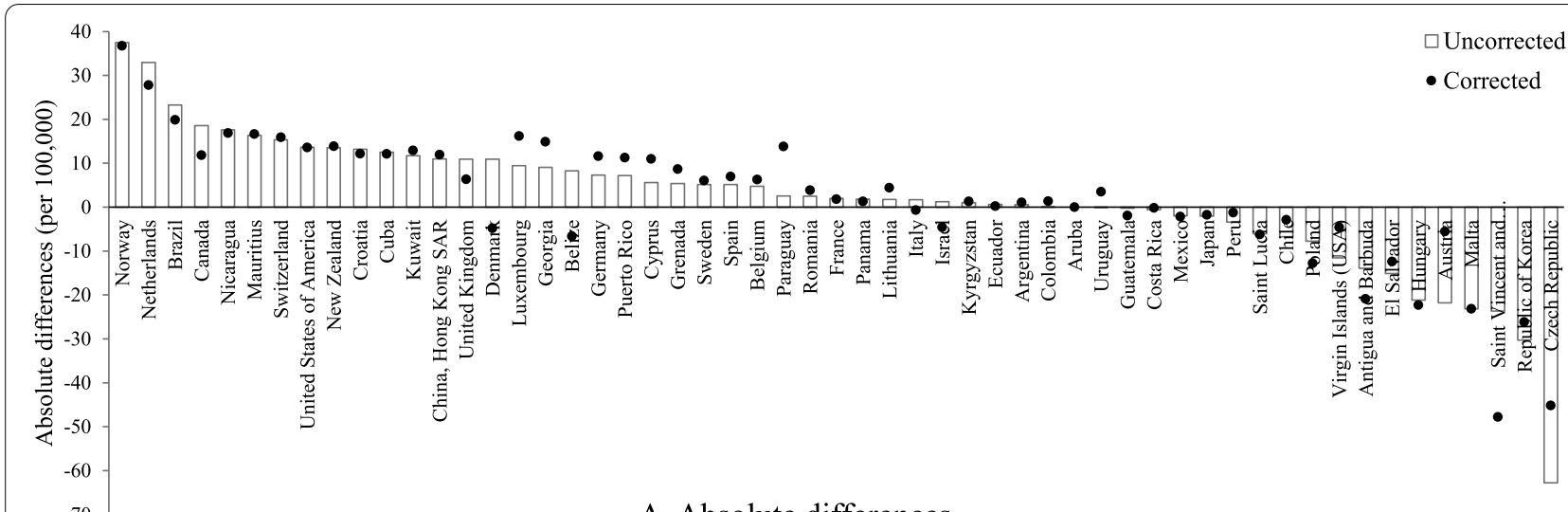

A. Absolute differences

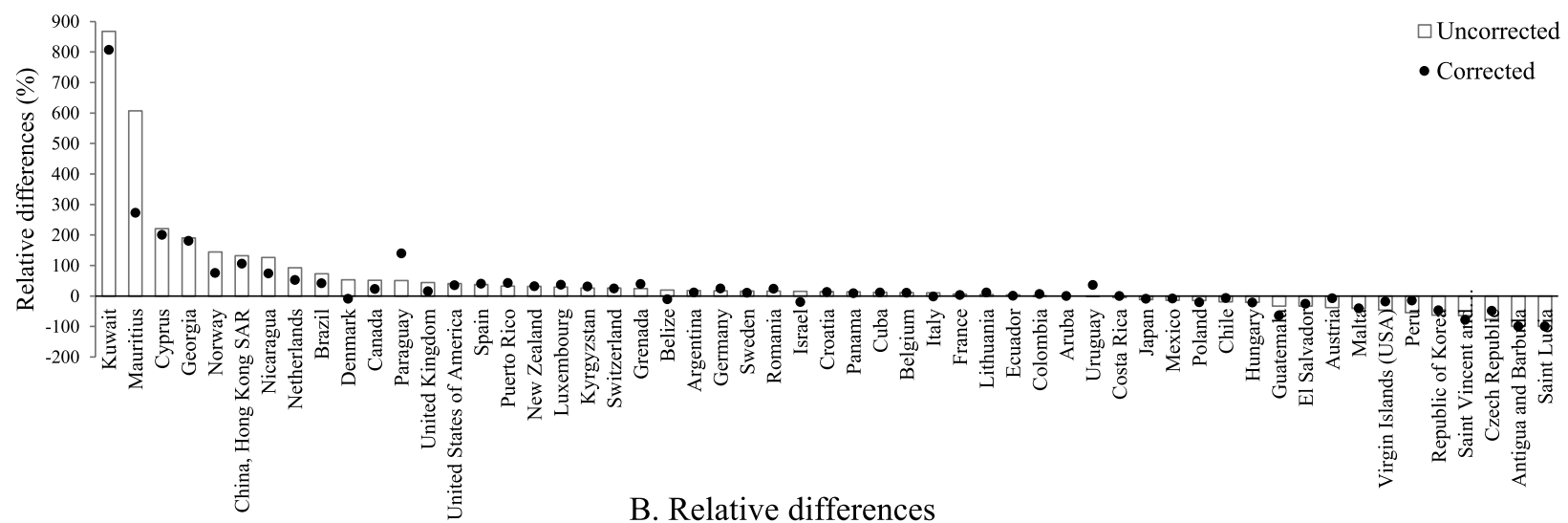

Fig. 4 Absolute and relative differences in age-adjusted unintentional fall mortality rates among older adults between 2005 and 2015 in $\mathbf{5 5}$ countries and territories before and after correcting data coding Notes: Uncorrected: Mortality rates that were not corrected to adjust for the impact of unspecified deaths, injury deaths with undetermined intent, and unspecified unintentional injury deaths. Corrected: Mortality rates after correction for the impact of unspecified deaths, injury deaths with undetermined intent, and unspecified unintentional injury deaths

codes yet, or still use non-standard ICD codes to gather death data [31] for their vital registration systems. Fourth, some countries/territories decline to submit their data to the WHO Mortality Database despite the fact that they possess the data. For example, Vietnam does not report data to the WHO Mortality Database regularly although it has had an established death registration system ("A6 death register") for almost 30 years [32]. These governments may worry about unwanted outcomes of submitting mortality data for public distribution, such as data misinterpretation or misuse, disruption of domestic legislation, and/or loss of data ownership [33].

\section{Coding quality}

We considered two types of evidence about coding quality. First, we considered problematic ICD codes for deaths in general by examining the rates of deaths with unspecified causes, injury deaths with undetermined intent, and unintentional injury deaths with unspecified causes. Replicating previous results from Mathers et al. [8] and Bhalla et al. [27], we found high proportions of such problematic codes across time and across countries/ territories.

Second, we considered two problematic codes within those deaths caused by unintentional falls among older adults: unintentional falls with unspecified mechanism and unintentional falls with unknown occurrence place. Our findings underscore the severity of two types of problematic codes. Problematic ICD codes were common for elderly unintentional fall mortality, with the proportions of unintentional falls with unspecified mechanism ranging from 50 to $66.67 \%$ and of unintentional falls with unknown occurrence place ranging from 33.33 to 100\% (see Additional file 1: Appendix 1).

Problematic codes are attributed to a range of factors in previous research, including a) lack of necessary knowledge and skills in disease diagnosis and use of 
Table 2 Regression coefficients of year on age-adjusted mortality rate in 82 countries/territories when uncorrected and corrected

\begin{tabular}{|c|c|c|c|c|c|}
\hline Country/territory & $b\left(S_{b}\right)$ & $b^{\prime}\left(S_{b^{\prime}}\right)$ & Country/territory & $b\left(S_{b}\right)$ & $b^{\prime}\left(S_{b^{\prime}}\right)$ \\
\hline Netherlands & $2.92(0.20)^{*}$ & $2.22(0.23)^{*}$ & Colombia & $0.10(0.06)$ & $0.10(0.06)$ \\
\hline Australia & $2.11(0.08)^{*}$ & $2.04(0.08)^{*}$ & Portugal & $0.10(0.41)$ & $0.52(0.51)$ \\
\hline Nicaragua & $1.94(0.24)^{*}$ & $2.23(0.31)^{*}$ & Barbados & $0.09(0.18)$ & $0.47(0.28)$ \\
\hline Canada & $1.91(0.18)^{*}$ & $1.33(0.13)^{*}$ & Morocco & $0.09(0.03)^{*}$ & $0.10(0.07)$ \\
\hline Georgia & $1.78(0.44)^{*}$ & $2.93(0.66)^{*}$ & Honduras & $0.03(0.25)$ & $0.16(0.28)$ \\
\hline Croatia & $1.50(0.37)^{*}$ & $1.30(0.29)^{*}$ & Israel & $0.02(0.04)$ & $-0.32(0.11)^{*}$ \\
\hline United States of America & $1.45(0.04)^{*}$ & $1.42(0.04)^{*}$ & Dominican Republic & $0.01(0.04)$ & $-0.03(0.08)$ \\
\hline Grenada & $1.39(0.64)^{*}$ & $2.22(1.05)$ & Costa Rica & $0.00(0.06)$ & $0.22(0.16)$ \\
\hline Chile & $1.02(0.33)^{*}$ & $1.20(0.31)^{*}$ & Peru & $-0.01(0.05)$ & $0.17(0.07)^{*}$ \\
\hline New Zealand & $1.01(0.20)^{*}$ & $1.03(0.20)^{*}$ & Guatemala & $-0.05(0.01)^{*}$ & $-0.29(0.07)^{*}$ \\
\hline Germany & $0.93(0.12)^{*}$ & $1.22(0.15)^{*}$ & Republic of Moldova & $-0.08(0.19)$ & $-0.21(0.22)$ \\
\hline Cyprus & $0.89(0.21)^{*}$ & $1.05(0.51)$ & Turkey & $-0.09(0.91)$ & $-0.48(0.81)$ \\
\hline Switzerland & $0.87(0.09)^{*}$ & $0.89(0.10)^{*}$ & Estonia & $-0.13(0.36)$ & $-0.13(0.36)$ \\
\hline United Kingdom & $0.87(0.10)^{*}$ & $0.60(0.12)^{*}$ & France & $-0.13(0.10)$ & $-0.44(0.19)^{*}$ \\
\hline Mauritius & $0.83(0.26)^{*}$ & $0.63(0.32)$ & Belize & $-0.15(0.75)$ & $-0.16(0.82)$ \\
\hline Sweden & $0.82(0.08)^{*}$ & $1.10(0.13)^{*}$ & Kyrgyzstan & $-0.15(0.07)^{*}$ & $-0.18(0.08)^{*}$ \\
\hline Brazil & $0.78(0.23)^{*}$ & $-0.29(0.37)$ & Japan & $-0.18(0.02)^{*}$ & $-0.16(0.02)^{*}$ \\
\hline Fiji & $0.73(0.51)$ & $1.33(1.14)$ & Singapore & $-0.20(0.25)$ & $-0.18(0.26)$ \\
\hline Saint Vincent and Grenadines & $0.65(0.51)$ & $0.56(0.72)$ & Aruba & $-0.23(0.49)$ & $-0.29(0.59)$ \\
\hline Puerto Rico & $0.64(0.21)^{*}$ & $0.92(0.23)^{*}$ & Panama & $-0.23(0.19)$ & $-0.64(0.22)^{*}$ \\
\hline Philippines & $0.58(0.14)^{*}$ & $0.78(0.27)^{*}$ & Virgin Islands (USA) & $-0.24(0.45)$ & $-0.13(0.46)$ \\
\hline Cuba & $0.52(0.28)$ & $0.59(0.29)$ & Argentina & $-0.25(0.07)^{*}$ & $-0.32(0.12)^{*}$ \\
\hline Bulgaria & $0.48(0.43)$ & $0.31(0.44)$ & Trinidad and Tobago & $-0.27(0.24)$ & $-0.46(0.39)$ \\
\hline China, Hong Kong SAR & $0.44(0.10)^{*}$ & $0.39(0.12)^{*}$ & Antigua and Barbuda & $-0.29(0.29)$ & $-0.33(0.46)$ \\
\hline Thailand & $0.44(0.02)^{*}$ & $0.72(0.05)^{*}$ & Mexico & $-0.34(0.04)^{*}$ & $-0.44(0.07)^{*}$ \\
\hline Spain & $0.42(0.05)^{*}$ & $0.54(0.07)^{*}$ & Venezuela & $-0.34(0.16)^{*}$ & $-0.66(0.17)^{*}$ \\
\hline Saint Lucia & $0.38(0.33)$ & $0.55(0.37)$ & Ireland & $-0.35(0.47)$ & $-0.02(0.45)$ \\
\hline Paraguay & $0.36(0.05)^{*}$ & $1.20(0.13)^{*}$ & Suriname & $-0.54(0.58)$ & $-0.91(0.69)$ \\
\hline Belgium & $0.35(0.13)^{*}$ & $0.34(0.16)$ & Jordan & $-0.61(0.32)$ & $-0.62(0.69)$ \\
\hline Luxembourg & $0.35(0.23)$ & $-0.46(0.39)$ & El Salvador & $-0.85(0.32)^{*}$ & $-0.88(0.41)^{*}$ \\
\hline Maldives & $0.34(1.07)$ & $1.07(1.77)$ & Republic of Korea & $-1.16(0.33)^{*}$ & $-0.81(0.35)^{*}$ \\
\hline Jamaica & $0.33(0.07)^{*}$ & $0.80(0.19)^{*}$ & Bahamas & $-1.20(0.69)$ & $-0.96(0.87)$ \\
\hline Lithuania & $0.32(0.18)$ & $0.49(0.17)^{*}$ & Austria & $-1.22(0.20)^{*}$ & $0.23(0.17)$ \\
\hline Latvia & $0.25(0.32)$ & $0.32(0.38)$ & Guyana & $-1.25(0.30)^{*}$ & $-2.02(0.72)^{*}$ \\
\hline Kuwait & $0.20(0.19)$ & $0.24(0.22)$ & Malta & $-1.33(0.50)^{*}$ & $-1.37(0.50)^{*}$ \\
\hline Haiti & $0.19(0.23)$ & $0.18(0.50)$ & Poland & $-1.44(0.20)^{*}$ & $-1.86(0.22)^{*}$ \\
\hline Italy & $0.19(0.07)^{*}$ & $-0.08(0.09)$ & Sri Lanka & $-1.88(0.24)^{*}$ & $-1.78(0.23)^{*}$ \\
\hline Romania & $0.17(0.05)^{*}$ & $0.26(0.06)^{*}$ & Norway & $-2.59(0.69)^{*}$ & $-0.94(0.46)$ \\
\hline Ecuador & $0.16(0.08)$ & $0.13(0.12)$ & Denmark & $-3.66(0.82)^{*}$ & $-3.63(0.57)^{*}$ \\
\hline Iceland & $0.13(0.48)$ & $1.32(0.52)^{*}$ & Hungary & $-5.50(0.49)^{*}$ & $-5.46(0.48)^{*}$ \\
\hline Uruguay & $0.11(0.04)^{*}$ & $0.34(0.08)^{*}$ & Czech Republic & $-6.37(0.40)^{*}$ & $-5.57(0.43)^{*}$ \\
\hline
\end{tabular}

Notes: b, regression coefficients when uncorrected; b', regression coefficients when corrected;

* $p$-value $\leq 0.05$

ICD codes by medical practitioners and coders [34-37]; b) heavy workload for medical practitioners and coders [38]; and c) lack of work enthusiasm for many coders $[39,40]$.

\section{Influence of problematic codes}

Three previous studies examined recent trends in elderly unintentional fall mortality in the United States and suggested that the recent mortality increases in elderly 
unintentional fall may be partially related to the improvement in coding practice rather than entirely to actual increases in the rates of the falls [15-17]. This finding raises concerns about global data.

By examining global rather than only United States data, our research considered additional relevant indicators to assess the quality related to elderly unintentional fall mortality. We found that the first three types of problematic codes had a varying influence on elderly unintentional fall mortality across countries/territories and over time for some countries/territories.

More broadly, we replicated previous reports from the United States [15-17] and found that poor-quality data may seriously or moderately bias estimates of unintentional fall mortality in many countries/territories. With imprecise coding, estimates may be significantly distorted and comparisons of mortality rates across countries/territories and over time appear even to be subverted in some cases. These findings emphasize the need to attend carefully to the reporting quality of crude data when using the WHO Mortality Database for injury prevention research and policy-making.

\section{Policy implications}

Our findings raise several policy implications. First, there is urgent need to improve data availability of the WHO Mortality Database. For countries/territories without an established vital registration system, resources should be directed to develop a system that can collect high-quality data. WHO has developed programs, guidelines and tools, including a World Health Data Hub, to aid these countries/territories [41-44]. For countries that collect mortality data but do not report it to the WHO, efforts should be made to clarify the significance of data-sharing to support both global and national health decision-making and development of health policy.

Second, global and national efforts should be taken to improve the quality of elderly unintentional fall mortality data. This may require addressing the challenge of improving infrastructure capacities in many LMICTs, including recruiting and maintaining adequate and qualified medical certifiers to code data. Regular inspections of data should be conducted in a rigorous manner to detect and correct problematic disease diagnoses and ICD codes. Information technologies (e.g., automatic machine learning models based electronic health records) could be introduced to improve data accuracy $[45,46]$.

Last, researchers and policy-makers should be aware of the limitations of the crude data included in the WHO Mortality Database and consider how to clean and/or interpret the data given those limitations. The WHO might consider organizing a group of experts to assess the quality of mortality data in the WHO Mortality Database and standardize a correction approach to resolve data issues and release corrected data estimates. The WHO might also organize a team to conduct a systematic review of national policy documents for mortality data collection to help understand the reasons for poor data availability and low data quality and to identify corresponding solutions.

\section{Study limitations}

This study was primarily limited by lack of external information that is needed to systematically assess data quality. Without such information, we relied on proxies like problematic data coding but were unable to fully assess completeness and misclassification of mortality data. In related areas like road traffic mortality data, underreporting and or over-reporting are demonstrated by comparing health data with highway safety reports [47]. We also were unable to examine misclassification of data. Among old adults, a minor or moderate fall injury may lead to death after a lengthy interval [48]. In those cases, especially as the time interval increases, the underlying cause of death may be coded as a terminal illness rather due to an unintentional fall, and our data were unable to uncover such situations [49].

Further, because we were unable to gather policy documents concerning mortality data collection for each country/territory included in the WHO Mortality Database due to language barriers and/or unavailability of relevant documents, we cannot conduct a systematic analysis of policy documents to explore factors influencing data availability and reporting quality. Future research might address this question. Finally, the linear regression analysis that we conducted may not capture non-linear time trends in age-adjusted unintentional fall mortality.

\section{Conclusion}

Despite global efforts across many years, the availability and quality of data related to elderly unintentional fall mortality in the WHO Mortality Database is poor. Data availability and quality were comparatively worse in LICTs in Africa, Southern Asia and Oceania. Varying data quality across countries/territories or over time have substantial impact on mortality estimates and comparisons of mortality across time and across countries.

We recommend continued global and national efforts to increase the availability and quality of unintentional fall mortality data in the WHO Mortality Database. While that happens, researchers and policy-makers 
should interpret and use results based on crude data with caution. In addition, we recommend the WHO lead an effort to assess the quality of available mortality data in the WHO Mortality Database, develop correction approaches as needed, and provide corrected data for public use.

\begin{abstract}
Abbreviations
GATHER: Guidelines for Accurate and Transparent Health Estimates Reporting: GBD: Global Burden of Disease; HICTs: higher-income countries/territories (HICTs); ICD: International Classification of Disease; LICTs: low-income countries/territories; LMICTs: lower middle-income countries/territories; SDGs: Sustainable Development Goals; UMICTs: upper middle-income countries/ territories; UN: United Nations; WHO: World Health Organization; WPP: World Population Prospects.
\end{abstract}

\section{Supplementary Information}

The online version contains supplementary material available at https://doi. org/10.1186/s12877-021-02744-3.

Additional file 1: Appendix 1. Coding quality by county/territory income. Appendix 2. Country-specific coding quality. Appendix 3. Crude and corrected age-adjusted unintentional fall mortality. Appendix 4. Flow chart of selection of eligible countries/territories. Appendix 5. GATHER checklist

\section{Acknowledgements}

Not applicable.

\section{Authors' contributions}

JH1 (Junjie Hua), PN, PC, ZR, JH2 (Jieyi He), WX, LL, YF, RL, JL, WW, DCS and GH all contributed to the design of the study, acquisition and validation of the underlying data, statistical analysis, interpretation of the data, and writing the manuscript. GH and JH1 conceived the study. PN, PC, ZR and LL helped design the research and analyze the data. JH2, WX, YF, RL, JL and WW helped acquire, validate and interpret data. LL, DCS and GH critically reviewed the manuscript. All authors read and approved the final manuscript.

\section{Authors' information}

$J H 1$, Ph.D. Candidate; PN, Lecturer; PC, Postdoctoral fellow; ZR, Postdoctoral fellow; JH2, Ph.D. Candidate; WX, Ph.D. Candidate; LL, Lecturer; YF, Ph.D. Candidate; RL, Ph.D. Candidate; JL, Ph.D. Candidate; WW, Ph.D. Candidate; DCS, Professor, GH, Professor.

\section{Funding}

This study was funded by the Natural Science Foundation of Hunan Province, China (Grant No. 2020JJ4764) and the Project Program of National Clinical Research Center for Geriatric Disorders (Xiangya Hospital) (Grant No. 2020LNJJ14). The funders had no role in in the design of the study and collection, analysis, and interpretation of data and in writing the manuscript should be declared.

\section{Availability of data and materials}

Datasets for the current study are available in the WHO Mortality Database, https://www.who.int/data/data-collection-tools/who-mortality-database, and UN World Population Prospects 2019, https://population.un.org/wpp/Downl oad/Standard/Population/.

\section{Declarations}

\section{Ethics approval and consent to participate}

The research protocol was approved by the Medical Ethics Committee of Central South University on 25 January 2021 (No. XYGW-2021-06). This study used national registration data for secondary analysis, does not involve clinical/ personal data, and was exempted from requirements for informed consent to participate.

\section{Consent for publication}

Not applicable.

\section{Competing interests}

The authors declare that they have no competing interests.

\section{Author details}

${ }^{1}$ Department of Epidemiology and Health Statistics; Hunan Provincial Key Laboratory of Clinical Epidemiology, Xiangya School of Public Health; National Clinical Research Center for Geriatric Disorders, Xiangya Hospital, Central South University, Changsha 410078, China. ${ }^{2}$ Department of Psychology, University of Alabama at Birmingham, Birmingham, AL 35294, USA.

Received: 19 September 2021 Accepted: 27 December 2021

Published online: 24 January 2022

\section{References}

1. Rao C. Elements of a strategic approach for strengthening national mortality statistics programmes. BMJ Glob Health. 2019;4(5):e001810.

2. World Health Organization. Monitoring health for the SDGs. Available from: https://www.who.int/data/gho/data/themes/world-health-stati stics. Accessed 9 Sept 2021

3. World Health Organization. WHO Mortality Database. Available from: https://www.who.int/data/data-collection-tools/who-mortality-database. Accessed 9 Sept 2021.

4. United Nations Population Fund. Trends in maternal mortality: 2000 to 2017. Available from: https://www.unfpa.org/featured-publication/ trends-maternal-mortality-2000-2017. Accessed 9 Sept 2021.

5. Naghavi M, Abajobir AA, Abbafati C, Abbas KM, Abd-Allah F, Abera SF, et al. Global, regional, and national age-sex specific mortality for 264 causes of death, 1980-2016: a systematic analysis for the global burden of disease study 2016. Lancet. 2017;390(10100):1151-210.

6. Autier $\mathrm{P}$, Boniol $\mathrm{M}, \mathrm{G}$ avin $\mathrm{A}$, Vatten $\sqcup$. Breast cancer mortality in neighbouring European countries with different levels of screening but similar access to treatment: trend analysis of WHO mortality database. BMJ. 2011;343:d4411.

7. Ebmeier S, Thayabaran D, Braithwaite I, Bénamara C, Weatherall M Beastly R. Trends in international asthma mortality: analysis of data from the WHO mortality database from 46 countries (1993-2012). Lancet 2017;390(10098):935-45.

8. Mathers CD, Fat DM, Inoue M, Rao C, Lopez AD. Counting the dead and what they died from: an assessment of the global status of cause of death data. Bull World Health Organ. 2005;83(3):171-7.

9. Mikkelsen L, Phillips DE, AbouZahr C, Setel PW, de Savigny D, Lozano R, et al. A global assessment of civil registration and vital statistics systems: monitoring data quality and progress. Lancet. 2015;386(10001):1395-406.

10. World Health Organization. WHO methods and data sources for countrylevel causes of death 2000-2019. Available from: https://www.who.int/ docs/default-source/gho-documents/global-health-estimates/ghe2019_ cod_methods.pdf?sfvrsn=37bcfacc_5. Accessed 9 Sept 2021.

11. World Health Organization. Falls. Available from: https://www.who.int/ news-room/fact-sheets/detail/falls. Accessed 9 Sept 2021.

12. World Health Organization. Ageing and health. Available from: https:// www.who.int/news-room/fact-sheets/detail/ageing-and-health. Accessed 9 Sept 2021.

13. Galet C, Zhou Y, Eyck PT, Romanowski KS. Fall injuries, associated deaths, and 30-day readmission for subsequent falls are increasing in the elderly US population: a query of the WHO mortality database and National Readmission Database from 2010 to 2014. Clin Epidemiol. 2018;10:1627-37.

14. Wu H, Mach J, Le Couteur DG, Hilmer SN. Fall-related mortality trends in Australia and the United Kingdom: implications for research and practice. Maturitas. 2020;142:68-72.

15. Hu G, Baker SP. An explanation for the recent increase in the fall death rate among older Americans: a subgroup analysis. Public Health Rep. 2012;127(3):275-81 
16. Maresh J, Guse C, Layde P. National trends and coding patterns in fallrelated mortality among the elderly in the United States. J Public Health Policy. 2012;33(2):202-14.

17. Kharrazi RJ, Nash D, Mielenz TJ. Increasing trend of fatal falls in older adults in the United States, 1992 to 2005: coding practice or reporting quality? J Am Geriatr Soc. 2015;63(9):1913-7.

18. United Nations. World Population Prospects. Available from: https://popul ation.un.org/wpp/. Accessed 9 Sept 2021.

19. World Health Organization. International Statistical Classification of Diseases and Related Health Problems 10th Revision. Available from: https:// icd.who.int/browse10/2019/en. Accessed 9 Sept 2021.

20. Centers for Disease Control and Prevention. External Cause of Injury Mortality Matrix for ICD-10. Available from: https://www.cdc.gov/nchs/ data/ice/icd10_transcode.pdf. Accessed 9 Sept 2021.

21. Hu G, Mamady K. Impact of changes in specificity of data recording on cause-specific injury mortality in the United States, 1999-2010. BMC Public Health. 2014;14:1010.

22. World Bank. World Bank Country and Lending Groups. Available from: https://datahelpdesk.worldbank.org/knowledgebase/articles/906519. Accessed 9 Sept 2021

23. World Health Organization. Age Standardization of Rates: A new WHO Standard. Available from: https://www.who.int/healthinfo/paper31.pdf. Accessed 9 Sept 2021

24. Stevens GA, Alkema L, Black RE, Boerma JT, Collins GS, Ezzati M, et al. Guidelines for accurate and transparent health estimates reporting: the GATHER statement. Lancet. 2016;388(10062):e19-23.

25. World Bank. Open Data for Sustainable Development. Available from: https://www.worldbank.org/en/topic/digitaldevelopment/brief/opendata-for-sustainable-development. Accessed 9 Sept 2021.

26. Organisation for Economic Co-operation and Development. Available from: https://www.oecd.org/gov/digital-government/6th-oecd-expert-groupmeeting-on-open-government-data-summary.pdf. Accessed 9 Sept 2021.

27. Bhalla K, Harrison JE, Shahraz S, Fingerhut LA. Global burden of disease injury expert $\mathrm{G}$. availability and quality of cause-of-death data for estimating the global burden of injuries. Bull World Health Organ. 2010;88(11):831-8C.

28. Rao C, Gupta M. The civil registration system is a potentially viable data source for reliable subnational mortality measurement in India. BMJ Glob Health. 2020;5(8).

29. Zarocostas J. Libya: war and migration strain a broken health system. Lancet. 2018;391(10123):824-5.

30. Douedari Y, Howard N. Perspectives on rebuilding health system governance in opposition-controlled Syria: a qualitative study. Int J Health Policy Manag. 2019;8(4):233-44.

31. World Health Organization. WHO Mortality Database. Available from: https://www.who.int/news-room/q-a-detail/who-mortality-database. Accessed 9 Sept 2021

32. Stevenson MR, Ngoan le T, Hung DV, Huong Tu NT, Mai AL, Ivers RQ, et al. Evaluation of the Vietnamese A6 mortality reporting system: injury as a cause of death. Inj Prev 2012;18(6):360-364.

33. Zuiderwijk A, Janssen M. The negative effects of open government data investigating the dark side of open data. Proceedings of the 15th Annual International Conference on Digital Government Research - dgo '14 2014. p. 147-52.

34. Zwaan L, Singh $H$. Diagnostic error in hospitals: finding forests not just the big trees. BMJ Qual Saf. 2020;29(12):961-4.

35. Clark S. Help me trust you after my misdiagnosis. BMJ. 2021;373:n1175.

36. Lu TH, Lee MC, Chou MC. Accuracy of cause-of-death coding in Taiwan: types of miscoding and effects on mortality statistics. Int J Epidemiol. 2000;29(2):336-43.

37. Lorkowski J, Jugowicz A. Shortage of physicians: a critical review. Adv Exp Med Biol. 2021;1324:57-62.

38. Morken T, Rebnord IK, Maartmann-Moe K, Hunskaar S. Workload in Norwegian general practice 2018 - an observational study. BMC Health Serv Res. 2019;19(1):434.

39. Ahern RM, Lozano R, Naghavi M, Foreman K, Gakidou E, Murray CJ. Improving the public health utility of global cardiovascular mortality data: the rise of ischemic heart disease. Popul Health Metr. 2011;9:8.

40. Naghavi M, Richards N, Chowdhury H, Eynstone-Hinkins J, Franca E, Hegnauer $M$, et al. Improving the quality of cause of death data for public health policy: are all 'garbage' codes equally problematic? BMC Med. 2020;18(1):55
41. World Health Organization. Civil Registration and Vital Statistics Strategic Implementation Plan 2021-2025. Available from: https://apps.who.int/ iris/bitstream/handle/10665/342847/9789240022492-eng.pdf?seque nce=1\&isAllowed=y. Accessed 9 Sept 2021.

42. World Health Organization. SCORE data collection tool. Available from: https://www.who.int/data/data-collection-tools/score. Accessed 9 Sept 2021.

43. World Health Organization. Tools and Standards for SCORE Essential Interventions. Available from: https://www.who.int/publications/i/item/ tools-and-standards-for-score-essential-interventions. Accessed 9 Sept 2021.

44. World Health Organization. World health statistics 2021: monitoring health for the SDGs, sustainable development goals. Available from: https://apps.who.int/iris/bitstream/handle/10665/342703/9789240027 053-eng.pdf. Accessed 9 Sept 2021.

45. Startsev N, Dimov P, Grosche B, Tretyakov F, Schuz J, Akleyev A. Methods for ensuring high quality of coding of cause of death. The mortality register to follow southern Urals populations exposed to radiation. Methods Inf Med. 2015;54(4):359-63.

46. Jeblee S, Gomes M, Jha P, Rudzicz F, Hirst G. Automatically determining cause of death from verbal autopsy narratives. BMC Med Inform Decis Mak. 2019;19(1):127.

47. Huang $H$, Yin Q, Schwebel DC, Ning P, Hu G. Availability and consistency of health and non-health data for road traffic fatality: analysis of data from 195 countries, 1985-2013. Accid Anal Prev. 2017;108:220-6.

48. Baker SP, O'Neill B, Haddon W Jr, Long WB. The injury severity score: a method for describing patients with multiple injuries and evaluating emergency care. J Trauma. 1974;14(3):187-96.

49. University of Otago, Injury Prevention Research Unit. New Zealand Injury Prevention Strategy indicators of injury death: are we counting all the cases? Available from: http://psm-dm.otago.ac.nz/ipru/ReportsPDFs/ OR085.pdf. Accessed 9 Sept 2021.

\section{Publisher's Note}

Springer Nature remains neutral with regard to jurisdictional claims in published maps and institutional affiliations.
Ready to submit your research? Choose BMC and benefit from:

- fast, convenient online submission

- thorough peer review by experienced researchers in your field

- rapid publication on acceptance

- support for research data, including large and complex data types

- gold Open Access which fosters wider collaboration and increased citations

- maximum visibility for your research: over $100 \mathrm{M}$ website views per year

At BMC, research is always in progress.

Learn more biomedcentral.com/submissions 